\title{
Do Women Have Evolved Mate Preferences for Men with Resources? A Reply to Smuts
}

\author{
David M. Buss \\ University of Michigan, Ann Arbor, Michigan
}

\begin{abstract}
Research by more than 50 scientists studying more than 10,000 individuals inhabiting 33 countries, six continents, and five islands supports the hypothesis that women have evolved mate preferences for men who show cues of resource possession or resource acquisition potential. Smuts' (1991) apparent view that these species-typical preferences do not exist is contravened by the scientific evidence. Repeated assertions that "behaviors depends on context" do not illuminate our understanding in the absence of specifying which behaviors, which contexts, and which evolved mechanisms are activated by the relevant contextual input. Progress in the study of evolution and human behavior depends on using key terms in consensually defined rather than idiosyncratic ways, on distinguishing evolved psychological mechanisms from manifest behavior, and on giving greater weight to cumulative scientific evidence than to subjective impressions.
\end{abstract}

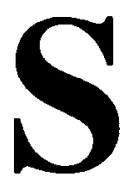

muts (1991) takes issue with Tooby and Cosmides' (1990) reading of his commentary on my international research on the evolution of human mate preferences (Buss 1989). I have no wish to discuss the broader debate between different evolutionary approaches to human behavior, as I have done so extensively elsewhere (Buss 1991). I do wish to correct some misconceptions that have developed because two scientific issues are at stake, one specific and one more far reaching: (1) whether human females have evolved species-typical mate preferences for males who manifest cues to resources and resource acquisition potential and (2) how the field can clarify thinking about evolved psychological mechanisms, contextual input, and manifest behavior. Much of the disagreement disappears when certain conceptual distinctions are made, and it is clear that Smuts and I agree on many essential points (Smuts, March 24, 1991, personal communication).

Received March 8, 1991; revised May 3, 1991.

Address reprint requests and correspondence to: David M. Buss, Department of Psychology, University of Michigan, Ann Arbor, MI 48109-1346. 


\section{SCIENTIFIC EVIDENCE VERSUS SUBJECTIVE IMPRESSIONS}

Smuts apparently gives great credence to his subjective impressions. Throughout his response to Tooby and Cosmides, he reports about what he "admires," tells readers about his "skepticism," his "thoughts," and his "suspicions." He reports that the predictions about sex differences in preferences for mates with resources "strike[s] [him] as a . . reflection of a particular modern view of appropriate human sex roles" (note that I never used the term "roles," a word that often obscures more than it reveals, nor have I ever offered prescriptions about what is "appropriate" for the sexes). He offers his "reading" and "thoughts" about various ethnographies, and his "opinion" about the mate preferences of women. Fortunately, a process for resolving differences in opinions and subjective impressions exists-the scientific method.

That method has now produced overwhelming evidence, using diverse techniques, dozens of diverse cultures, and dozens of investigators working in dozens of locations around the world, that human females in fact do have preferences for males who possess resources and attributes known to be linked with resource acquisition (e.g., Betzig 1987; Buss 1987, 1989; Sadalla et al. 1987; Symons 1979; Townsend 1989; and references therein). No published study of humans on this lopic that I am aware of has ever failed to find the predicted sex differences in human mate preferences. Smuts is certainly entitled to his opinions, and is also entitled to dispute the findings, but he doesn't really address them. Nor are arguments marshaled about why the scientific findings from so many different sources might be wrong. Nor are readers presented with any altcrnative human findings that might contradict the overwhelming evidence that now exist on what women actually prefer in mates. Why should subjective impressions be given greater credence than findings from 10.047 people studied by 50 scientists in 33 countries throughout the world?

\section{BEHAVIOR DEPENDS ON EVOLVED PSYCHOLOGICAL MECHANISMS AND CONTEXTUAL INPUT TO MECHANISMS, NOT SIMPLY ON CONTEXT ALONE}

Repeated assertions that "behavior depends on context" do not illuminate our knowledge and understanding of the psychology of human mate preferences, without specifying what behaviors, what contexts, and what mechanisms are being activated by those contexts. As I pointed out several years ago, of course behavior depends on context. I have never asserted that female mate preferences are "obligate" in the sense of invariably manifest in behavior regardless of context, and indeed have specified what some of these likely contexts are-the existence of resources that can be accrued 
and defended, the presence of men who vary in the resources they can offer, and the presence of men who are sometimes willing to channel those resource to a women and her children (Buss 1989, p. 2).

A key point is that my argument was not about manifest behavior, but rather about the psychology of mate preferences. Thus, Smuts erroneously attributes to me a view of "uniform female mate-choice behavior," a view that I nowhere endorsed or implied (p. 2; italics added). I see the distinction between underlying mechanisms and manifest behavior as crucial for understanding human mating strategies. Many things affect actual mate choice behavior-parental preferences, one's own mate value, the existing sex ratio, the availability of mates possessing the desired qualities, the nature of the mating system, the importance of other mate preferences that may be more important in certain contexts, and so on (Buss 1989, in press). Mate preferences are clearly only one determinant of actual mate choice behavior. Not all women are able to actualize their preferences and secure mates with resources. Not all men possess resources, and some that do fail to invest them in women and their children. But none of these observations implies the nonexistence of a species-wide female preference for men with resources.

Perhaps Smut's failure to make the distinction between psychological preferences and manifest mating behavior caused some of the confusion, misunderstanding, and argumentation at cross-purposes.

\section{THE SCIENTIFIC EVIDENCE OF WOMEN'S MATE PREFERENCES ACROSS CONTEXTS}

Smuts reiterates that context matters, and on this point we agree. It would advance our understanding more to provide theoretical arguments and scientific evidence about which contexts matter and why. My own research team has recently explored the effects of temporal context on mate preferences (Buss and Schmitt 1991). For example, women prefer immediate access to resources in short-term mating contexts, but value cues to future resource acquisition in long-term mating contexts. Temporal context is surely only onc of the important contextual inputs into the mechanisms. But we should not ignore the scientific evidence for women's preferences for men with resources and resource acquisition cues that has been found across contexts (for a partial list of relevant references, see Betzig 1987; Buss 1987, 1989, in press; Daly and Wilson 1983; Ellis, in press; Kenrick et al. 1990; Sadalla and Kenrick 1987; Symons 1979; Townsend 1989, and the references contained therein). Women's preferences for men with resource cues have been documented across:

1) Different cultures

2) Different racial groups

3) Different ethnic groups 
4) Different political systems (e.g., capitalism, communism, socialism)

5) Women of differing socioeconomic status levels

6) Women of different personal income levels

7) Countries on six continents and five islands

8) Tribal, agrarian, and industrial societies

9) Polygynous and non-polygynous mating systems

10) Widely disparate ecological and geological conditions

11) Women of different religions

12) Women possessing different levels of education

13) Women of different ages, from 14 through 60

14) Women who are single, married, and divorced

15) Women desiring children and women not desiring children

16) Women who have children and women who do not

17) Women in large cities and women in rural settings.

I venture to say that women's preferences to mate with men possessing resources and cues to resource acquisition are the most extensively documented findings in the human mating literature, with the exception of the equally documented finding that men worldwide prefer to mate with women who are young and physically attractive (Buss 1989; Cunningham 1986; Darwin 1871; Symons 1979). At this stage of scientific inquiry, the burden of proof must shift to those who are still skeptical and who express opinions that differ from the weight of the scientific evidence.

\section{MUST MALE PARENTAL INVESTMENT BE NECESSARY FOR FEMALE REPRODUCTIVE SUCCESS IN ORDER FOR WOMEN TO EVOLVE A PREFERENCE FOR MEN WITH RESOURCES?}

Smuts argues that a species-typical female preference for men with resources could have evolved "only if male parental investment was consistently reliable and necessary for female reproductive success during our evolutionary past"' (1989, p. 2; italics added). Natural selection, however, does not require something to be necessary for reproductive success, only that it confer a reproductive advantage. Nor is it necessary that the resources be "consistently reliable" in the sense of temporal reliability or in the sense of prolonged or lifelong investment. Indeed, short-term mating strategies by women often involve an exchange of sex for temporary (hence not "consistently reliable") resources such as meat (Malinowski 1929; Shostack 1981; Burley and Symanski 1981). There is no necessity whatsoever for male resources to have been necessary for female reproductive success. What is required is that securing such resources through mating gave women in human evolutionary history a reproductive advantage over women who did 
not secure them, and that the reproductive benefits derived outweighed the reproductive cost entailed in the mechanism and choice. Women do and probably did in our ancestral past raise children without the aid of a man's resources. Sometimes they are forced to by virtue of a mate's death, a poor mate choice, the presence of males who are unable or unwilling to invest, or the inability to secure the resources of those men who are willing to invest. Their survival and reproductive success in human ancestral conditions, however, may have been lower than comparable women who did secure a man's resource investment (Hill 1989).

\section{WHICH RESOURCE CUES DO WOMEN PREFER?}

Robert Smuts endorses Barbara Smuts' (1985) hypothesis that in some nonhuman primates, females choose males not for their resources, but for protection against other aggressive males - a hypothesis also advanced in abbreviated form by Trivers (1972). Finding that male mates perform one function, however, does not negate the possibility of their performing other functions. I expect that among humans women prefer mates both for cues to resource possession and resource acquisition potential (a hypothesis already confirmed) and for cues to their ability and willingness to protect them-a hypothesis that has recently received supporting evidence from my research lab (Buss and Schmitt, under review).

A man's ability and willingness to protect a woman and her children, it may be noted, is itself a "resource," albeit a different kind. Thus, I agree with Smuts' implicit suggestion that women may have evolved preferences to mate with men who show cues to a variety of resources, not all of which are material or economic. Such cues may include prestige, status, and reputation (which need to be accrued and defended, but in a different sense than tangible external resources); hunting skills and prowess as a warrior (which also need to be acquired, but also in a different sense than external resources); leadership skills and ability to form coalitions; talents and capacities to enlist the aid of others; ability and willingness to defend the female and children against aggressors (Buss 1989, p. 2); and parental skills such as ability and willingness to teach children and provide opportunities for learning, modeling, and emulation. These cues to male resource possession and resource acquisition potential, as well as the cues to male protection of females suggested by Smuts, are worthy of empirical examination. Furthermore, it would advance the ficld to develop a more comprehensive taxonomy of the different sorts of reproductively relevant resources that individuals can confer on a potential mate. Surely women's and men's mate preferences are sufficiently complex that they include a number of diverse resources. 


\section{TERMINOLOGY AND THE PROGRESS OF EVOLUTIONARY PSYCHOLOGY}

In addition to clarifying conceptual issues, several terminological issues should be noted. Smuts attributes to Buss (1989) the notion that "women have been equipped by natural selection with a uniform preference for rich males" and "a universal preference for rich males" (italics added). Nowhere does the term "rich" appear in the Buss (1989) article, and the caricature of the argument trivializes it. I have reported elsewhere that it is not the rich or "wealthy" that females prefer (Buss and Barnes 1986). The original article was precise on this issue: "Females, more than males, should value attributes in potential mates such as ambition, industriousness, and earning capacity that signal the possession or likely acquisition of resources" (Buss 1989 , p. 2). Smuts did add a statement that he is using rich to refer to attributes that do "not necessarily include great wealth." But rich has a specific meaning in English usage: "possessing great material wealth" (American Heritage Dictionary, Second Edition, 1976). Progress in evolutionary psychology depends on using key terms in consensually defined ways.

Another apparent confusion is Smuts' attribution to me the notion that "biology makes it necessary for males to compete for resources and females to choose the winning males." Nowhere in my article is this sort of genetic deterministic argument made. Quite to the contrary, I identified some of the crucial contextual factors upon which such a mate preference by females might hinge: "In species with male parental investment, such as Homo sapiens (Alexander and Noonan 1979), females should seek to mate with males who have the ability and willingness to provide resources ... only in contexts where resources can be accrued, monopolized, and defended, where males tend to control such resources, and where male variance is sufficiently high" (Buss 1989, p. 2). The hypothesis was one of a context-dependent preference, not a "biological necessity for a behavior." Indeed, the great pains I took to show that the expressed preferences I found were sometimes manifested in actual mating decisions highlighted my distinction between evolved psychological mechanisms and manifest behavior - a distinction further clarified by Tooby and Cosmides (1989).

\section{CONCLUSIONS}

The cumulative weight of the scientific evidence supports the hypothesis that human females have evolved species-typical psychological mate preferences for mates who display cues to resources and resource acquisition. In the field of evolution and human behavior, this is surely one of the most powerfully supported evolutionary hypotheses, having been documented extensively across cultures, age groups, generations, races, ethnic groups, mating systems, tribal groups, and modern industrial societies. Perhaps if most 
other evolutionary hypotheses about humans had such empirical confirmation, the field would not suffer the reputation of being composed primarily of speculations, "just so stories," and opinions.

The emerging field of evolutionary psychology can make much progress if scientists distinguish clearly between evolved psychological mechanisms and manifest behavior, if terms are used in consensually defined ways, and if we give greater weight cumulative scientific evidence than to subjective impressions.

I thank Bruce Ellis, Cindy Rehfues, Robert Smuts, and Don Symons for useful comments about the conceptual issues contained in this article.

\section{REFERENCES}

Alexander, R.D., and Noonan, K.M. Concealment of ovulation, parental care, and human social evolution. In Evolutionary Biology and Human Social Behavior: An Anthropological Perspective, N.A. Chagnon and W.B. Irons (Eds.). Massachusetts: Duxbury Press, 1979.

American Heritage Dictionary, Second Edition, 1976.

Betzig L. Mating and parenting in Darwinian perspective. In Human Reproductive Behavior: A Darwinian Perspective, L. Betzig, M. Borgerhoff Mulder, and P. Turke (Eds.). Cambridge: Cambridge University Press, 1987.

Burley, N., and Symanski, R. Women without: An evolutionary and cross-cultural perspective on prostitution. In The Immoral Landscape: Female Prostitution in Western Societies, R. Symanski (Ed.). Toronto: Butterworths, 1981.

Buss, D.M. Sex differences in human mate selection criteria: An evolutionary perspective. In Sociobiology and Psychology, C. Crawford, D. Krebs, and M. Smith (Eds.). Hillsdale, New Jersey: Erlbaum, 1987.

- Sex differences in human mate preferences: Evolutionary hypotheses tested in 37 cultures. Behavioral and Brain Sciences 12: 1-49, 1989.

- Evolutionary personality psychology. Annual Review of Psychology. Palo Alto, California. Annual Reviews, Inc, 1991.

- Mate preference mechanisms: Implications for partner choice and intrasexual competition. In The Adapted Mind: Evolutionary Psychology and the Generation of Culture, J. Barkow, L. Cosmides, and J. Tooby (Eds.). New York: Oxford University Press, in press.

-- , and Barnes, M. Preferences in human mate selection. Journal of Personality and Social Psychology 50: 559-570, 1986.

- and Schmitt, D. Sexual Strategies Theory: A Contextual Evolutionary Analysis of Human Mating, under review.

Cunningham, M.R. Measuring the physical in physical attractiveness: Quasi-experiments on the sociobiology of female beauty. Journal of Personality and Social Psychology 50: 925-935, 1986.

Daly, M., and Wilson, M. Sex, Evolution, and Behavior. Boston: Willard Grant Press, 1983. Darwin, C. The Descent of Man and Selection in Relation to Sex. London: Murray, 1871.

Ellis, B.E. The evolution of sexual attraction: Evaluative mechanisms in women. In The Adapted Mind: Evolutionary Psychology and the Generation of Culture, J. Barkow, L. Cosmides, and J. Tooby (Eds.). New York: Oxford, in press.

Hill, K. Evolution of the Termination of Female Reproduction in Homo Sapiens. Presentation to the Evolution and Human Behavior Program, January 12, 1989.

Kenrick, D.T., Sadalla, E.K., Groth, G., and Trost, M.R. Gender and trait requirements in a 
mate: An evolutionary bridge between personality and social psychology. Journal of Personality 58: 97-116, 1990.

Malinowski, B. The Sexual Life of Savages in North-Western Melanesia. London: Routledge, 1929.

Sadalla, E.K., Kenrick, D.T., and Vershure. B. Dominance and heterosexual attraction. Journal of Personality and Social Psychology 52: 730-738, 1987.

Shostack, M. Nisa: The Life and Words of a !Kung Women. Cambridge, Massachusetts: Harvard University Press, 1981.

Smuts, B.B. Sex and Friendship in Baboons. Hawthorn, New York: Aldine, 1985.

Smuts, R.W. The present also explains the past: A response to Tooby and Cosmides. Ethology and Sociobiology 12: 77-82, 1991.

Symons, D. The Evolution of IIuman Sexuality. New York: Oxford, 1979.

Tooby, J., and Cosmides, L. The innate versus the manifest: How universal does universal have to be? Behavioral and Brain Sciences 12: 36-37, 1989.

- and - The past explains the present: Emotional adaptations and the structure of ancestral environments. Ethology and Sociobiology 11(4/5), 375-424, 1990.

Townsend, J.M. Mate selection criteria: A pilot study. Ethology and Sociobiology 10: 241$254,1989$.

Trivers, A. Parental investment and sexual selection. In Sexual Selection and the Descent of Man: 1871-1971, B. Campbell (ed). Chicago: Aldine, pp. 136-179, 1972. 